
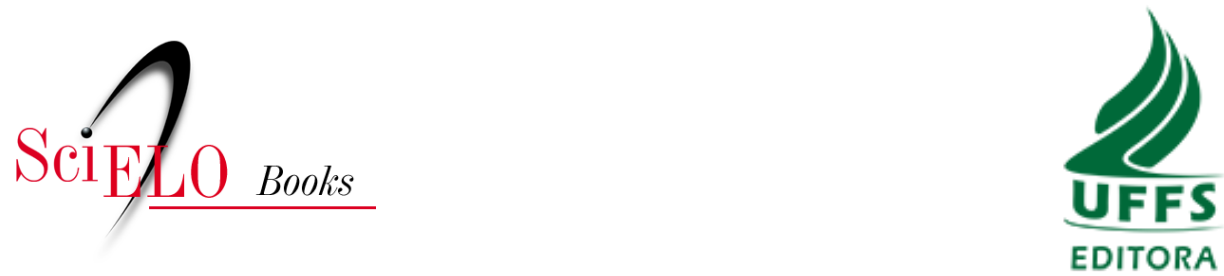

Parte V - Desenvolvimento e novas tecnologias produtivas e sociais

\title{
Capítulo 1 - Incubadora tecnossocial de cooperativas e empreendimentos econômicos solidários como articuladora da educação ambiental em Cerro Largo
}

\author{
Luís Henrique Teixeira Franqui \\ Luciana Scherer \\ Louise de Lira Röedel Botelho
}

\section{SciELO Books / SciELO Livros / SciELO Libros}

FRANQUI, L.H.T., SCHERER, L., and BOTELHO, L.L.R. Incubadora tecnossocial de cooperativas e empreendimentos econômicos solidários como articuladora da educação ambiental em Cerro Largo. In: ROTTA, E., LAGO, I.C., JUSTEN, A.F., and SANTOS, M., eds. Conhecimento em rede: desenvolvimento, cooperação e integração regional em território de fronteira - Rede CIDIR: 10 anos [online]. Chapecó, SC: Editora UFFS, 2019, pp. 260-277. ISBN: 978-65-5019-011-8. https://doi.org/10.7476/9786586545432.0016.

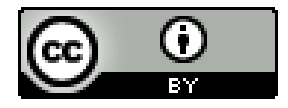

All the contents of this work, except where otherwise noted, is licensed under a Creative Commons Attribution 4.0 International license.

Todo o conteúdo deste trabalho, exceto quando houver ressalva, é publicado sob a licença Creative Commons Atribição 4.0. 


\title{
INCUBADORA TECNOSSOCIAL DE COOPERATIVAS E EMPREENDIMENTOS ECONÔMICOS SOLIDÁRIOS COMO ARTICULADORA DA EDUCAÇÃO AMBIENTAL EM CERRO LARGO
}

\author{
Luís Henrique Teixeira Franqui ${ }^{1}$ \\ Luciana Scherer ${ }^{2}$ \\ Louise de Lira Röedel Botelho ${ }^{3}$
}

1 Mestre em Desenvolvimento e Políticas Públicas (UFFS - Campus Cerro Largo, 2017). Graduado em Direito (IESA, 2015). Jornalista. Advogado. Contato: lhfranqui@hotmail.com

2 Professora na Universidade Regional Integrada do Alto Uruguai e das Missões (URI). Doutoranda em Desenvolvimento Regional (UNIJUÍ). Mestre em Ciências Sociais (PUCRS). Graduada em Turismo (PUCRS) e Administração de Empresas (UFRGS). Contato: lucianascherer@yahoo.com.br

3 Professora adjunta II na Universidade Federal da Fronteira Sul (UFFS) - Campus Cerro Largo. Doutora em Engenharia e Gestão do Conhecimento (EGC/UFSC). Mestre em Engenharia e Gestão do Conhecimento (EGC/UFSC). Especialista em Formação para Docentes (UNIVALI). MBA Executivo em Administração Global (Universidade Lusófona de Lisboa). Contato: louisebotelho@gmail.com 


\section{INTRODUÇÃO}

A Universidade Federal da Fronteira Sul (UFFS) é uma instituição multicampi, com campi nos três estados do Sul: em Santa Catarina, o Campus Chapecó, além da Reitoria; no Rio Grande do Sul, os campi estão em Cerro Largo, Erechim e Passo Fundo; no Paraná, os campi localizam-se em Laranjeiras do Sul e Realeza. Em Cerro Largo, a UFFS iniciou atividades em 2010, e uma de suas ações é o desenvolvimento de conhecimentos acerca da economia solidária, o que faz de forma significativa por meio da Incubadora Tecnossocial de Empreendimentos de Economia Solidária (ITCEES), que será apresentada na sequência deste capítulo.

Matarazzo \& Boeira (2016, p. 208) lembram que no campo da economia solidária, no fim da década de 1990, surgiu no Brasil "um tipo de organização denominado incubadora tecnológica de cooperativas populares (ITCP), que, com o passar dos anos, expandiu-se e se tornou uma rede, fundamentalmente composta por atores vinculados às universidades públicas e comunitárias". Em 1997 foi criado o Programa Nacional de Incubadoras de Cooperativas Populares (PRONINC), tendo como signatários a Financiadora de Estudos e Projetos (FINEP), o Banco do Brasil, a Fundação Banco do Brasil e o Centro de Orientação e Encaminhamento Profissional. O programa acabou institucionalizado pelo governo federal, por meio do Decreto $\mathrm{n}^{\circ} 7.357$, de 17/11/2010, tendo como um dos objetivos "a geração de trabalho e renda, a partir da organização do trabalho, com foco na autogestão e dentro dos princípios de autonomia dos empreendimentos econômicos solidários" (BRASIL, 2010).

As ITCPs têm como objetivo promover o desenvolvimento local sustentável através da assessoria sistemática às organizações e aos empreendimentos populares solidários. Com a intenção de "dar condições aos grupos ou empreendimentos para que possam ter oportunidades melhores de trabalho e renda através da cooperação e da solidariedade, resgatando a cidadania e permitindo que os envolvidos se sintam capazes de tornarem atores do próprio desenvolvimento" (PEREIRA, 2007). Elas buscam articular multidisciplinarmente áreas de conhecimento de universidades brasileiras, com grupos populares interessados em gerar trabalho e renda, visando contribuir na formação de cooperativas populares e ou empresas autogestionárias. Sua atuação se dá em um duplo sentido, na 
formação dos estudantes, por meio da vinculação do ensino, da pesquisa e da extensão, e na geração de trabalho e renda (GUERRA, 2008).

Culti (2007, p. 5) destaca as incubadoras universitárias como empreendimentos que constroem tecnologias sociais, cada vez mais empregados no campo de geração de trabalho e renda: "são espaços que agregam professores, pesquisadores, técnicos e acadêmicos de diversas áreas do conhecimento. [...] com o objetivo de atender trabalhadores que tencionam organizar seus próprios empreendimentos [...]". Para efetivar a atuação das ITCPs com os grupos beneficiários, nesse caso os empreendimentos incubados, há o processo chamado incubação. Tal processo baseia-se em uma metodologia de trabalho a ser realizado entre ITCP e incubado, essa metodologia diferencia-se de ITCP para ITCP, mas geralmente envolve desde o primeiro contato, sua aceitação, formação, assessoria, acompanhamento até sua saída da ITCP, ou seja, sua desincubação. Para isso, contam com metodologias participativas de incubação, de transferência de tecnologias e práticas baseadas em gestão social.

O estudo que constitui este capítulo valeu-se da metodologia qualitativa de pesquisa, em sintonia com o método de abordagem indutivo, sendo a revisão bibliográfica e a análise documental as principais técnicas de coleta de dados, juntamente com a observação participante das práticas sociais, políticas e ambientais acerca do tratamento de resíduos sólidos no município de Cerro Largo. A técnica de observação participante surgiu como uma oportunidade de aproximação das perspectivas dos sujeitos envolvidos, bastante útil para descobrir aspectos novos de um problema, indo além, mas sem desconsiderar os elementos epistemológicos das teorias obtidas em estudos, pesquisas documentais e bibliográficas.

O capítulo está estruturado, além desta introdução, da seguinte forma: o primeiro tópico dá ênfase à formação e aos objetivos da ITCEES, bem como o desenvolvimento do programa Pensar o Amanhã; o segundo discorre sobre a educação ambiental e o Comitê de Educação Ambiental, com as principais atividades planejadas para sensibilização da comunidade cerro-larguense; no terceiro, analisa-se a experiência do Comitê para a Organização de Cooperativa de Catadores, que já apresenta seus primeiros resultados concretos, como a criação da Cooperativa de Trabalho de Catadores Unidos Pela Natureza (COOPERCAUN); e no quarto são debatidos a PNRS e os desafios do Comitê Técnico 
Ambiental, que busca solucionar a questão referente à destinação final dos RSU em Cerro Largo. Nas considerações finais são elencados os resultados já obtidos pelo programa Pensar o Amanhã e seus três projetos interligados.

\section{A ITCEES e a busca de resolução de problemas socioambientais coletivos}

No ano de 2013, a Incubadora Tecnossocial de Empreendimentos de Economia Solidária (ITCEES) da UFFS - Campus Cerro Largo se constituiu inicialmente via projeto de extensão, por meio de aprovação em edital do Programa de Extensão Universitária (PROEXT 2014/MEC/SESU), que possibilitou os recursos necessários para a sua formação. Posteriormente, por intermédio de editais internos da própria UFFS e aprovação em Chamada do Ministério da Ciência, Tecnologia e Inovação (MCTI) e da Secretaria Nacional de Economia Solidária (SENAES) - chamadas MCTI/SECIS/MTE/SENAES/CNPq no 89/2013 e UNIVERSAL - MCTI/CNPq N 14/2014 -, a ITCEES foi oficializada e sua institucionalização se efetivou com a aprovação do Regimento Interno. Assim, em 24 de fevereiro de 2015 foi editada e aprovada a Resolução 01/2015 do Conselho do Campus da UFFS - Cerro Largo, criando a ITCEES, que, conforme o art. $1^{\circ}$ deste regimento, é uma

\footnotetext{
estrutura laboratorial do Campus Cerro Largo de natureza inter e multidisciplinar, que visa desenvolver a incubação e o fortalecimento de empreendimentos cooperativos e/ou autogestionários vinculados à economia solidária, presenciais e/ou à distância, por meio de ações de sensibilização, capacitação, treinamento e assessoramento integradas a projetos e/ou programas de pesquisa e/ou extensão em caráter temporário, com vistas a contribuir na promoção do desenvolvimento local e regional. (2015, p. 2).
}

A missão da ITCEES é ser um local no qual se desenvolvem ações de incubação e cooperação em cooperativas e empreendimentos econômicos solidários, atuando "como espaço de estudos, pesquisa-ação, extensão e desenvolvimento de tecnologias voltadas à organização do trabalho coletivo, com foco na sustentabilidade e autogestão dos empreendimentos" (art. 2º 2015, p. 2). A intenção da ITCEES é promover os princípios do cooperativismo e do associativismo nos empreendimentos incubados (grupos beneficiados) a fim de que 
esses empreendimentos construam suas próprias formas de trabalho coletivo, baseados na autogestão de seus próprios empreendimentos, promovendo o desenvolvimento sustentável local e os princípios da economia popular solidária. O público-alvo da ITCEES são pessoas que se encontram à margem do setor econômico capitalista, que atuam em pequenos empreendimentos cooperativos, como na agricultura familiar e na coleta e reciclagem, através dos catadores. Sua visão é atuar por meio de processo político-pedagógico mediado pelo uso de tecnologias sociais, "como forma de apoio e incentivo à formação e consolidação de empreendimentos econômicos autogestionários, potencializando práticas sociais emancipatórias e promovendo o desenvolvimento regional" (art. $3^{\circ}$, 2015 , p. 2). E, entre outros, são objetivos da incubadora: desenvolver processos de incubação norteados pela perspectiva da autogestão; manter parcerias em ações planejadas e desenvolvidas pelos cursos de graduação e pós-graduação da Universidade; potencializar a geração de tecnologias sociais por meio da inovação social; contribuir com a formação de estudantes, etc.

O trabalho da ITCEES está na articulação com diferentes instituições e espaços da esfera pública, na busca para resolução de problemas socioambientais coletivos. Uma de suas frentes de atuação é a educação ambiental (EA), com a pretensão de solucionar um constante problema que assola o município de Cerro Largo, que é a questão dos resíduos sólidos urbanos (RSU), um problema de interesse público que envolve diferentes atores sociais como o Poder Executivo, catadores, associações, empresas, moradores, professores, estudantes, etc. A organização da atuação da ITCEES em educação ambiental pode ser visualizada na Figura 1, descrita ao longo desta seção.

Figura 1 - Atuação da ITCEES em Educação Ambiental

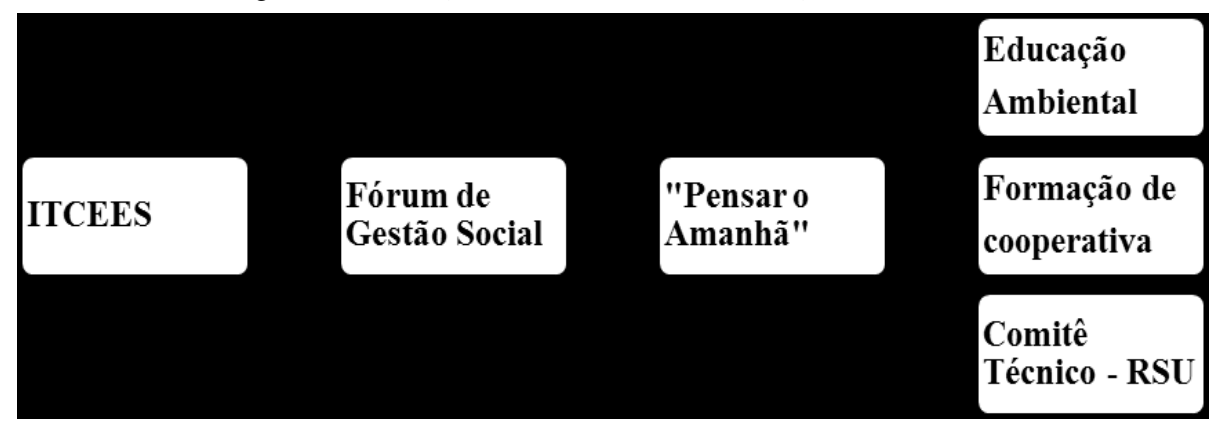

Fonte: Elaborada pelos autores. 
Dentre as atividades promovidas pela ITCEES está o Fórum de Gestão Social, com foco em questões sociais e ambientais que envolvem o município de Cerro Largo. Esse fórum teve início em agosto de 2016, sendo constituído por diferentes atores sociais, empenhados na construção de alternativas para solucionar um problema coletivo do município. Sua coordenação é representada por professores da ITCEES, e seus membros são agentes sociais da sociedade civil organizada. Como representantes, destacam-se Prefeitura de Cerro Largo, Secretaria Municipal de Educação e Cultura (SMEC), Câmara de Vereadores, URI-Cerro Largo, Ministério Público/RS, Defensoria Pública/RS, Cáritas Diocesana, Emater/RS-Ascar, Corsan, Lions Clube, Leo Clube, Rotary Club, Rotaract Club, Ambiental SS, professores, técnicos e alunos da UFFS, munícipes e catadores (aqui entendidos como agentes ambientais).

O objetivo do Fórum é ser um agente de coordenação e fomento das atividades coletivas para a resolução dos RSU em nível local. Dessa forma, como encaminhamento deste órgão, foi criado conjuntamente com os parceiros o programa de extensão "Educação ambiental nas escolas e na comunidade de Cerro Largo visando um meio ambiente ecologicamente equilibrado - Pensar o Amanhẫ. O programa envolve os cursos de Administração, Engenharia Ambiental e o Mestrado em Desenvolvimento e Políticas Públicas da UFFS - Cerro Largo, com previsão para durar 24 meses e início em $1^{\circ}$ de maio de 2017. Seu objetivo principal "é despertar a percepção da sociedade acerca dos problemas ambientais e contribuir para a conscientização, mobilização e atendimento da Política Nacional de Resíduos Sólidos (PNRS)”. (ITCEES, 2017, p. 10).

No Fórum foram organizados três comitês com objetivos específicos e metas concomitantes e interligadas a serem cumpridas, incorporando frentes de trabalho relevantes para a solução dos problemas socioambientais de Cerro Largo: Comitê de Educação Ambiental, que fará atividades educativas nas escolas, capacitação para os catadores de lixo e a sensibilização da comunidade para a questão da coleta seletiva do lixo; Comitê para Organização de Cooperativa de Catadores, que já está constituída; e o Comitê Técnico Ambiental, que buscará soluções e alternativas para o problema da destinação final dos RSU.

Como o programa Pensar o Amanhã tem como objetivo fomentar na sociedade a mudança de consciência ambiental e propor políticas públicas que visem equacionar problemas socioambientais e estimular o desenvolvimento 
sustentável é preciso promover práticas de educação ambiental, como instrumento de desenvolvimento e cidadania.

\section{A EDUCAÇÃO AMBIENTAL E A SENSIBILIZAÇÃO DA COMUNIDADE}

Educar ambientalmente significa reduzir os custos ambientais, na medida em que a população poderá proteger o meio ambiente, fixar a ideia de consciência ecológica e buscar sempre a utilização de tecnologias limpas (FIORILLO, 2015, p. 134). A Resolução no 2 do Conselho Nacional de Educação (CNE) estabeleceu as Diretrizes Curriculares Nacionais para a educação ambiental e, no seu art. $2^{\circ}$, conceituou que a "Educação Ambiental é uma dimensão da educação, é atividade intencional da prática social, que deve imprimir ao desenvolvimento individual um caráter social em sua relação com a natureza e com os outros seres humanos, visando potencializar essa atividade humana com a finalidade de torná-la plena de prática social e de ética ambiental" (BRASIL, 2012).

A legislação brasileira traz uma série de previsões sobre a educação ambiental, que apareceu inicialmente na Política Nacional do Meio Ambiente (PNMA), Lei $\mathrm{n}^{\circ} 6.938 / 1981$, que no art. $2^{\circ}$ elenca alguns princípios, como no inciso X: "Educação ambiental a todos os níveis de ensino, inclusive a educação da comunidade, objetivando capacitá-la para participação ativa na defesa do meio ambiente" (BRASIL, 1981).

A educação ambiental prevista na PNMA foi recepcionada pela Constituição de 1988, sendo uma das principais bases legais o art. 225, parágrafo $1^{\circ}$, inciso VI, onde consta que "para assegurar a efetividade desse direito, incumbe ao Poder Público "promover a educação ambiental em todos os níveis de ensino e a conscientização pública para a preservação do meio ambiente" (BRASIL, 2016, p. 75).

No final da década de 1990, o legislador nacional deu ênfase ainda maior à educação ambiental, editando a Política Nacional de Educação Ambiental (PNEA), com a Lei no 9.795/1999. O artigo primeiro traz um conceito jurídico de educação ambiental, enquanto o segundo estabelece ampla abrangência à iniciativa: 
Art. $1^{\circ}$. Entendem-se por educação ambiental os processos por meio dos quais o indivíduo e a coletividade constroem valores sociais, conhecimentos, habilidades, atitudes e competências voltadas para a conservação do meio ambiente, bem de uso comum do povo, essencial à sadia qualidade de vida e sua sustentabilidade.

Art. $2^{\circ}$. A educação ambiental é um componente essencial e permanente da educação nacional, devendo estar presente, de forma articulada, em todos os níveis e modalidades do processo educativo, em caráter formal e não-formal. (BRASIL, 1999).

Mais recentemente, após a implantação da PNRS, com a Lei n ${ }^{\circ} 12.305 / 2010$, a necessidade de estimular a educação ambiental novamente foi reforçada. Tanto que no artigo $8^{\circ}$ da norma são elencados os instrumentos da referida política, entre outros, a educação ambiental no inciso VIII (BRASIL, 2010).

A educação ambiental também é tutelada no mundo jurídico pelo princípio da educação ambiental, influenciado pela Declaração da Conferência das Nações Unidas sobre o Meio Ambiente Humano, de Estocolmo, que prevê em seu princípio 19 que "é indispensável um esforço para a educação em questões ambientais, dirigida tanto às gerações jovens como aos adultos e que preste a devida atenção ao setor da população menos privilegiada, para fundamentar as bases de uma opinião pública bem informada [...]" (ONU, 1972).

O Comitê de Educação Ambiental da ITCEES está desenvolvendo um projeto de extensão de Educação Ambiental em ambientes escolares, que visa o desenvolvimento de ações de educação ambiental nas escolas, atuando na figura de uma ferramenta que promova conscientização para o desenvolvimento sustentável. A ideia é fazer com que se atente para a apreensão de estudantes e de toda comunidade escolar sobre as questões acerca da problemática do meio ambiente para que através de uma tática que visa mobilizar os atores envolvidos nos ambientes escolares - direção, coordenação pedagógica, professores e alunos se possa atender a PNRS (UFFS, 2017a).

Além do projeto de extensão de EA no âmbito das escolas municipais, o Comitê de Educação Ambiental está envolvido em outras atividades de sensibilização da comunidade, como a elaboração e distribuição maciça de um fôlder informativo sobre a coleta seletiva do lixo, que está sendo retomada no 
município ${ }^{4}$ com apoio e incentivo da ITCEES; a reativação do projeto de reciclagem de gordura saturada ${ }^{5}$, principalmente óleo comestível, com a reinstalação de ecopontos em diversos estabelecimentos comerciais e públicos, juntamente com a formalização de convênio com a empresa Reco Óleo, do município de Horizontina (RS), que fará o recolhimento e o processamento do produto; e também o desenvolvimento de atividades de formação junto aos catadores associados a COOPERCAUN.

Mesmo que muitas ações já venham sendo desenvolvidas desde o começo de 2017, o lançamento oficial das atividades do Comitê de Educação Ambiental ocorreu no dia $1^{\circ}$ de junho ${ }^{6}$, na abertura da Semana Nacional do Meio Ambiente, em solenidade realizada na Escola Municipal Pe. José Schardong, ocasião em que foram apresentados o programa, os projetos e suas proposições para a gestão ambiental no município de Cerro Largo.

\section{A COLETA SELETIVA E A ARTICULAÇÃO DOS CATADORES}

É interessante lembrar que "diferentemente do que ocorre na esmagadora maioria das nações desenvolvidas, o Brasil não está diminuindo a quantidade de resíduos gerada por seu sistema econômico, nem em termos absolutos, nem quando o cálculo é feito per capita" (ABRAMOVAY et al., 2013, p. 19). Conforme dados do Panorama dos Resíduos Sólidos no Brasil 2014, da Associação Brasileira de Empresas de Limpeza Pública e Resíduos Especiais (ABRELPE), 3.608 municípios apresentam iniciativas de coleta seletiva (2014, p. 41). A coleta seletiva de RSU é definida pela legislação, como "a coleta de resíduos sólidos previamente segregados conforme sua constituição ou composição” (BRASIL, 2010).

A quantidade de RSU coletados em 2014 cresceu em todas as regiões, em comparação ao dado de 2013. Mesmo com uma legislação mais restritiva e

4 Várias iniciativas visando à coleta seletiva de lixo foram feitas em Cerro Largo. O jornal Folha da Produção (1993, p. 1), em sua edição $\mathrm{n}^{\circ} 1.099$, noticia que alunos do $2^{\circ}$ ano do ensino médio do Colégio La Salle Medianeira foram recebidos pelo prefeito Adair José Trott, quando apresentaram um projeto de coleta seletiva. Depois, a gestão do prefeito René José Nedel (2009/2012) lançou nova campanha para a coleta seletiva, com intensa divulgação, mas que acabou não tendo continuidade.

5 O jornal Folha da Produção (2011, p. 5), em sua edição no 2.014, traz a informação do lançamento de um projeto de coleta e reciclagem de gordura saturada, numa iniciativa do Rotary Club Cerro Largo.

6 Folha da Produção, edição no 2.331, de 8 de junho de 2017, página 3. 
apesar dos esforços empreendidos em todas as esferas governamentais, a destinação inadequada de RSU se faz presente em todas as regiões e estados brasileiros e 3.334 municípios, correspondentes a 59,8\% do total, ainda fazem uso de locais impróprios para destinação final dos resíduos coletados. O mercado de limpeza urbana no país novamente apresentou evolução, que foi registrada em todas as regiões, e movimentou recursos que superaram a casa dos $\mathrm{R} \$ 26,5$ bilhões. Por sua vez, os recursos aplicados pelos municípios em 2014 para fazer frente a todos os serviços de limpeza urbana no Brasil foram, em média, de cerca de R $\$ 10,00$ por habitante por mês (ABRELPE, 2014, p. 38-39). Especificamente sobre a coleta seletiva de RSU, os dados da ABRELPE demonstram, por regiões do país, os percentuais de municípios com alguma iniciativa de coleta seletiva: Norte, 53,1\%; Nordeste, $42,8 \%$; Centro-Oeste, $37,5 \%$; Sudeste, $85 \%$; e Sul, $84,7 \%$ (2014, p. 42).

Em contraposição, reportagem publicada no Blog do Planeta, da revista Época, e assinada pelo jornalista Bruno Calixto, afirma que 85\% dos brasileiros não têm acesso à coleta seletiva e que pouco mais de 1.000 municípios contam com o sistema e destinam os RSU para reciclagem. O texto ampara-se num estudo "encomendado pelo Cempre, o Compromisso Empresarial para a Reciclagem, $\mathrm{e}$ mostra que quase 170 milhões de brasileiros não são atendidos por coleta seletiva em suas cidades" (CALIXTO, 2016). “Segundo a pesquisa, 1.055 municípios têm programas de coleta seletiva. Como o Brasil tem mais de 5mil cidades, esse número representa apenas $18 \%$ dos municípios". (CALIXTO, 2016). O mesmo texto faz menção, inclusive, a algumas cidades em que a quantidade de material que está sendo reciclado caiu entre 2014 e 2016, como é o caso de Brasília. "A capital federal reciclou 3.700 toneladas de lixo por mês em 2014. Em 2016, esse valor caiu para 2.600 toneladas por mês" (CALIXTO, 2016).

Como se percebe, os dados referentes à coleta e reciclagem de RSU no Brasil ainda são precários e inconsistentes. Isso reforça ainda mais a mobilização da sociedade em torno deste tema, não deixando de levar em conta também as peculiaridades do trabalho desempenhado pelos catadores, muito importante em todo o sistema que envolve a reciclagem. Medeiros \&Macedo destacam que dentre as alternativas de tratamento para o lixo urbano, a reciclagem configura-se como "importante elemento, pois possibilita o reaproveitamento de materiais descartados novamente ao circuito produtivo e traz benefícios ambientais 
através da economia de recursos naturais, energia e água" (2006, p. 69). Pereira Neto (2011, p. 77) salienta, ainda, que "os principais mecanismos de operacionalidade da PNRS, tanto da coleta seletiva como da logística reversa, priorizam a participação e a atuação estratégica e incisiva dos catadores de resíduos e suas cooperativas".

Diante deste cenário, o Comitê para Organização de Cooperativa de Catadores vem trabalhando desde 2016 quando, em 13 de dezembro, foi fundada a Cooperativa de Trabalho de Catadores Unidos pela Natureza (COOPERCAUN), com sede administrativa na rua Bernardo Jose Psiuk, no 279, e que atualmente encontra-se em fase de legalização, mas que já vem atuando informalmente desde a criação.

O projeto de extensão de sensibilização e capacitação dos catadores, vinculado ao programa Pensar o Amanhã, visa atuar no auxílio da capacitação de catadores de materiais recicláveis e reutilizáveis, no intuito de promover a apresentação de ações técnicas de segregação e gestão dos Resíduos Sólidos Urbanos, principalmente no município de Cerro Largo (ITCEES, 2017). Além disso, esse projeto, através da instrução desses catadores para a realização da correta segregação dos resíduos, busca assegurar a melhor qualidade dos materiais, facilitando a reciclagem e gerando a possibilidade de corresponder a um preço de mercado diferenciado junto às indústrias recicladoras (UFFS, 2017b).

Em 2017, muitas atividades já foram realizadas junto aos catadores ${ }^{7}$ : reunião do Comitê de Organização da Cooperativa, para decidir a utilização de verba da Cáritas Diocesana para aquisição de coletes, camisetas e adesivos (10 de março); encontro para divisão da rota de coleta e palestra sobre primeiros socorros, ministrada pela farmacêutica Marisane Basso (18 de abril); curso sobre manejo, alimentação e doenças dos cavalos, a cargo de José Emir Ramme, da Associação Amigos do Cavalo (25 de abril); reunião para entrega de coletes reflexivos (31 de abril); encontro para entrega da primeira remessa de luvas protetoras e de mudas, fornecidas para promover o cultivo de hortas domésticas (5 de maio); e a entrega de adesivos reflexivos para serem instalados nas gaiotas ${ }^{8}$ (12 de maio).

7 Atividades divulgadas regularmente na página da ITCEES na rede social Facebook. Vide: https:// www.facebook.com/incubadora.uffs?hc_ref=SEARCH

8 Pequena carroça de madeira, com duas rodas, puxada por um cavalo ou boi, bastante utilizada por agricultores no interior do Rio Grande do Sul e pelos catadores nas cidades gaúchas. 
Essas ações, diretamente relacionadas com os catadores de resíduos sólidos, entendidos nesse contexto como os agentes ambientais do programa, visam à construção de um elo entre as ações políticas, sociais e ambientais. Acredita-se que por meio de intervenção direta, cria-se uma perspectiva de tecnologia social baseada no empoderamento desses agentes para a construção dos primeiros passos para uma gestão ambiental.

\section{O DESAFIO DA DESTINAÇÃO FINAL DOS RSU}

A educação ambiental, a conscientização da comunidade, a coleta seletiva, a articulação dos catadores e a destinação dos resíduos sólidos urbanos são temas que se comunicam, sendo concomitantes e complementares. E a destinação final dos RSU é um desafio enorme para a sociedade contemporânea. Para Bauman (2008, p. 19), "os encontros dos potenciais consumidores com os potenciais objetos de consumo tendem a se tornar as principais unidades na rede peculiar de interações humanas conhecida, de maneira abreviada, como sociedade de consumidores". Essa sociedade de consumo, que estimula a produção desenfreada de bens, muitos dos quais supérfluos ou luxos desnecessários, tende a produzir resíduos de maneira crescente e ilimitada, causando sérios problemas na questão da destinação de todo esse lixo.

Todo ano, o mundo produz aproximadamente 1,3 bilhão de toneladas de resíduos sólidos. Conforme o Banco Mundial, em dados do relatório "What a Waste: A Global Review of Solid Waste Management"', a geração de lixo per capita praticamente duplicou nos últimos anos, chegando a impressionantes 1,2 quilo pessoa/dia. E a previsão é que essa produção anual chegue a 2,2 bilhões de toneladas até 2025, passando a produção diária per capita para 1,42 quilo (WORLD BANK, 2012, p. 8).Os dados da ABRELPE indicam que "a geração total de RSU no Brasil em 2014 foi de aproximadamente 78,6 milhões de toneladas, o que representa um aumento de $2,9 \%$ de um ano para outro, índice superior à taxa de crescimento populacional no país no período, que foi de 0,9\%” (2014, p. 28).

O perfil socioeconômico do Corede Missões, publicado em 2015 pela Secretaria de Planejamento do RS (SEPLAN), demonstra que os dados relativos a

9 Que desperdício: uma revisão global da gestão de resíduos sólidos. Tradução livre. 
domicílios com coleta de lixo por serviços de limpeza ou caçamba são insatisfatórios, apresentando uma média regional de 62,05\%, inferior às médias estadual $(92,08 \%)$ e nacional $(87,41 \%)$, com valores que oscilam entre $22,31 \%$ (Ubiretama) e 95,08\% (Cerro Largo) (SEPLAN, 2015, p. 29).

Para o Ministério do Meio Ambiente (MMA), a PNRS contém instrumentos importantes para o país enfrentar os problemas decorrentes do inadequado manejo dos RSU, antecipando a prevenção e a redução na geração de resíduos e uma série de instrumentos para aumentar a reciclagem e a reutilização de "resíduos sólidos (aquilo que tem valor econômico e pode ser reciclado ou reaproveitado) e a destinação ambientalmente adequada dos rejeitos (aquilo que não pode ser reciclado ou reutilizado) (MMA, 2017)". A PNRS também criou metas importantes que pretendem contribuir para a eliminação dos lixões. $\mathrm{O}$ art. 54 da Lei 12.305/2010 previu que "a disposição final ambientalmente adequada dos rejeitos, observado o disposto no $\$ 1^{\circ}$ do art. $9^{\circ}$, deverá ser implantada em até 4 (quatro) anos após a data de publicação desta Lei” (BRASIL, 2010), prazo que expirou e não foi atendido pela grande maioria dos municípios brasileiros, pois conforme a FIOCRUZ (2015), "a estimativa do Ministério do Meio Ambiente é que 59\% dos municípios brasileiros ainda dispõem seus resíduos em vazadouros a céu aberto ou aterros controlados (lixões com cobertura precária)".

Em Cerro Largo esse cenário não é diferente. O Compromisso de Ajustamento de Conduta firmado entre o Ministério Público do RS e o município mostra que o "lixão" localizado no Morro do Convento foi desativado "sem a competente elaboração de Plano de Remediação de Área Degradada” (MP/RS, 2017, p. 2). O documento lembra que, com a desativação do lixão, o município contratou empresa para o transporte e destinação dos RSU, mas que o transbordo dos resíduos estava sendo realizado na garagem municipal, um local não adequado, "uma vez que não possui licença ambiental, é realizado diretamente no solo, sem qualquer preparação, que o chorume ${ }^{10}$ não tem a destinação ambientalmente adequada" (MP/RS, 2017, p. 3). Mais grave ainda é o caso de o local de transbordo estar localizado a poucos metros de um poço de captação de água da CORSAN e próximo a um curso d'água.

10 Substância líquida resultante do processo de putrefação (apodrecimento) de matérias orgânicas. Este líquido é muito encontrado em lixões e aterros sanitários. É viscoso e possui um cheiro muito forte e desagradável. Caso não seja tratado, pode atingir lençóis freáticos, rios e córregos, levando a contaminação de recursos hídricos. 
Todos esses problemas, somados ao fato da área adquirida pelo município para instalar as futuras instalações de uma estação de triagem e transbordo ${ }^{11} \mathrm{de}$ RSU também estar localizada em área imprópria, que terá enormes dificuldades para obter o licenciamento ambiental, levou o Comitê Técnico Ambiental da ITCEES a enfrentar esta questão, mobilizando a academia, o poder público e a comunidade para, de forma articulada, encontrar alternativas viáveis a fim de fazer uma adequação mínima à legislação vigente. Nesse sentido, tal Comitê elaborou relatórios técnicos sobre melhorias e soluções para a implantação da logística reversa, avaliação de "lixão" desativado no município, central de triagem e transbordo, central de disposição de resíduos de construção civil e podas. Esses relatórios foram apresentados aos secretários municipais e ao Prefeito de Cerro Largo com o objetivo de apresentar o panorama da situação local e propor sugestões de melhoramentos e tomadas de decisões para a resolução da questão dos resíduos sólidos no município. Com esses relatórios, o Poder Público terá embasamento técnico para proceder a tomada de decisão.

\section{CONSIDERAÇÕES FINAIS}

A Incubadora Tecnossocial de Cooperativas e Empreendimentos Econômicos Solidários da UFFS-Cerro Largo vem articulando com diferentes instituições e espaços da esfera pública a busca pelo equacionamento de problemas sociais coletivos, tendo como uma de suas frentes de atuação a educação ambiental e uma de suas atividades de extensão o Fórum de Gestão Social, procurando soluções para a questão que envolve a destinação dos resíduos sólidos urbanos no município de Cerro Largo. Embora bastante recente, o programa de extensão "Educação ambiental nas escolas e na comunidade de Cerro Largo visando um meio ambiente ecologicamente equilibrado - Pensar o Amanhã, juntamente com seus três projetos vinculados, já apresentam os primeiros resultados concretos.

O Comitê de Educação Ambiental deu início ao projeto de extensão "Educação Ambiental aplicada à Educação Infantil e Anos Iniciais do Ensino Fundamental”, inicialmente nas escolas municipais Pe. José Schardong e Jacob Reinaldo

11 É um ponto de transferência intermediário de RSU coletados na cidade, criado em função da distância entre a área de coleta (Cerro Largo) e o local de destinação final (aterro sanitário da Companhia Riograndense de Valorização de Resíduos, localizado na rodovia VRS-867, km 02, em Giruá). 
Haupenthal, ambas em Cerro Largo. Além disso, elaborou um fôlder informativo que serve de apoio na retomada da coleta seletiva, vem atuando na reativação do projeto de reciclagem de gordura saturada e tem desenvolvido atividades de formação junto aos agentes de reciclagem ambiental do município e ministrado palestras sobre coleta seletiva em todas as escolas.

O Comitê para Organização de Cooperativa de Catadores já atingiu um de seus objetivos, com a fundação da Cooperativa de Trabalho de Catadores Unidos pela Natureza (COOPERCAUN) em dezembro de 2016. Agora atua no projeto "Sensibilização e capacitação dos catadores de resíduos recicláveis e reutilizáveis", para consolidar a cooperativa, instruir os catadores e, dessa forma, facilitar a reciclagem e aumentar a renda. Algumas ações realizadas: aquisição de camisetas, luvas, coletes e adesivos de segurança; definição da rota de coleta na cidade; realização de palestra sobre primeiros socorros; realização de curso sobre manejo, alimentação e doenças dos cavalos; fornecimento de mudas para o cultivo de hortas domésticas.

O maior desafio, porém, encontra-se na destinação final dos RSU, visando adequar o município à Política Nacional de Resíduos Sólidos (Lei. 12.305/2010). O Comitê Técnico da ITCEES tem mobilizado todos os segmentos da comunidade e, por enquanto, elaborou relatórios técnicos sobre melhorias e soluções para a implantação da logística reversa, avaliação do "lixão" desativado, central de triagem e transbordo e central para disposição dos RSU, que servirão de embasamento técnico para o Poder Público decidir os próximos encaminhamentos.

Como se percebe, são muitos os desafios envolvendo a educação ambiental, a coleta seletiva, o apoio aos catadores e a destinação final dos resíduos sólidos urbanos no município de Cerro Largo. O que já foi realizado até o momento permite acreditar que será possível atingir um dos principais objetivos propostos no regimento da ITCEES, que é contribuir na promoção do desenvolvimento sustentável local e regional.

\section{REFERÊNCIAS}

ABRAMOVAY, Ricardo; SPERANZA, Juliana Simões; PETITGAND, Cécile. Lixo zero, gestão de resíduos sólidos para uma sociedade mais próspera. São Paulo: Instituto Ethos, 2013. 
ABRELPE. Panorama dos Resíduos Sólidos no Brasil 2014. Disponível em: http://www.abrelpe.org.br/Panorama/panorama2014.pdf. Acesso em: 10 mar. 2017.

BAUMAN, Zygmunt. Trabajo, consumismo y nuevos pobres. Barcelona: Editorial Gedisa, 2000.

BRASIL. Política Nacional do Meio Ambiente. Lei no 6.938/1981. Disponível em: http://www.planalto.gov.br/ccivil_03/leis/L6938.htm. Acesso em: 12 maio 2017.

Constituição da República Federativa do Brasil de 1988. Porto Alegre: CORAG, 2016.

. Política Nacional de Educação Ambiental. Lei no 9.795/1999.

Disponível em: http://www.planalto.gov.br/ccivil_03/leis/L9795.htm. Acesso em: 12 maio 2017.

Política Nacional de Resíduos Sólidos. Lei n $12.305 / 2010$.

Disponível em: http://www.planalto.gov.br/ccivil_03/_ato20072010/2010/ lei/l-12305.htm. Acesso em: 12 maio 2017.

Decreto $\mathbf{n}^{\mathbf{0}} 7.357 / 2010$. Disponível em: https://www2.camara. leg.br/legin/fed/decret/2010/decreto-7357-17-novembro-2010-609509publicacaooriginal-130815-pe.html. Acesso em: 12 maio 2017.

Diretrizes Curriculares Nacionais para a Educação Ambiental.

Resolução no 2/2012. Disponível em: http://portal.mec.gov.br/dmdocuments/ publicacao13.pdf. Acesso em: 12 maio 2017.

CALIXTO, Bruno. 85\% dos brasileiros não têm acesso à coleta seletiva, mostra estudo. Disponível em: http://epoca.globo.com/colunas-e-blogs/ blog-do-planeta/noticia/2016/06/85-dos-brasileiros-nao-tem-acesso-coletaseletiva-mostra-estudo.html. Acesso em: 13 mar. 2017.

CULTI, Maria. Economia Solidária: Incubadoras Universitárias e Processo Educativo. Proposta, Rio de Janeiro, v. 31, n. 111, p.16-22, jan. 2007.

Disponível em: http://www.unitrabalho.uem.br/administracao/bd_artigos/ arquivos/010614153016.pdf. Acesso em: 11 maio 2017.

FIOCRUZ. Mesmo com sua extinção determinada por lei, lixões persistem como problema ambiental. 2015. Disponível em: https://portal.fiocruz.br/ $\mathrm{pt}$-br/content/revista-radis-chama-atencao-para-o-encerramento-do-prazopara-desativacao-dos-lixoes. Acesso em: 23 maio 2017.

FIORILlO, Celso Antonio Pacheco. Curso de Direito Ambiental Brasileiro. 16. ed. São Paulo: Saraiva, 2015. 
FINEP. Apoio e financiamento: PRONINC. Disponível em: http://www. finep.gov.br/apoio-e-financiamento-externa/historico-de-programa/proninc. Acesso em: 12 maio 2017.

GUERRA, Ana Carolina. Gestão das incubadoras tecnológicas de cooperativas populares: uma análise comparativa. 2008.

INCUBADORA TECNOSSOCIAL DE COOPERATIVAS E EMPREENDIMENTOS ECONÔMICOS SOLIDÁRIOS. Resolução 01/2015 do Conselho do Campus. Regimento Interno. Cerro Largo: UFFS, 2015. MATARAZZO, Gustavo; BOEIRA, Sérgio Luís. Incubação de cooperativas populares: representações sociais e tensões entre racionalidades. Caderno EBAPE.BR. Rio de Janeiro, v. 14, nº 1, artigo 10, p. 207-227, jan./mar. 2016.

MEDEIROS, Luiza Ferreira; MACEDO, Kátia Barbosa. Catador de material reciclável: uma profissão para além da sobrevivência? Psicologia \& Sociedade. 18 (2), p 62-71, maio/ago. 2006. Disponível em: http://www.scielo.br/pdf/ psoc/v18n2/08.pdf. Acesso em: 12 maio 2017.

MINISTÉRIO DO MEIO AMBIENTE. Política Nacional de Resíduos Sólidos. Disponível. Disponível em: http://www.mma.gov.br/ pol\%C3\%ADtica-de-res\%C3\%ADduos-s\%C3\%B3lidos. Acesso em: 23 maio 2017.

ONU. Declaração da Conferência das Nações Unidas sobre o Meio Ambiente Humano. Estocolmo: 1972. Disponível em: http://www.mma.gov. br/estruturas/agenda21/_arqui-vos/estocolmo.doc. Acesso em: 12 maio 2017. PEREIRA, José (Coord.). Gestão social da rede universitária de incubadoras tecnológicas de cooperativas populares na geração de trabalho e renda. Lavras. UFLA, 2007, projeto de pesquisa.

PEREIRA NETO, Tiago José. A Política Nacional de Resíduos sólidos: Os reflexos nas cooperativas de catadores e a logística reversa. Diálogo. Canoas, $\mathrm{n}^{\circ}$ 18, p. 77-96, jan./jun. 2011.

RIO GRANDE DO SUL. Compromisso de Ajustamento de Conduta. Ministério Público do RS e Município de Cerro Largo. Cerro Largo. 28 mar. 2017.

SECRETARIA DO PLANEJAMENTO, MOBILIDADE E DESENVOLVIMENTO REGIONAL DO RS. Perfil socioeconômico COREDE Missões. Disponível em: http://planejamento.rs.gov.br/upload/ arquivos/201603/28140705-perfis-regionais-2015-missoes.pdf. Acesso em: 12 maio 2017. 
UNIVERSIDADE FEDERAL DA FRONTEIRA SUL (UFFS). Pró-Reitoria de Extensão. Processos e ações de extensão da ITCEES (Incubadora Tecnossocial de Cooperativas e Empreendimentos Económicos Solidários) desafios e impactos para o desenvolvimento territorial sustentável e solidário das Regiões Noroeste e Missões do Estado do Rio Grande do Sul. Projeto de Extensão da Universidade Federal da Fronteira Sul - Campus Cerro Largo. Cerro Largo, RS, 2016. EDITAL No 522/UFFS/2016 (Apoio a Programas de Extensão).

. Pró-Reitoria de Extensão. Educação ambiental à educação infantil e anos iniciais do ensino fundamental. Educação ambiental nas escolas e na comunidade de Cerro Largo visando um meio ambiente ecologicamente equilibrado. Programa Pensar o Amanhã. Projeto de Extensão da Universidade Federal da Fronteira Sul - Campus Cerro Largo. Cerro Largo, RS, 2017a.

. Pró Reitoria de Extensão. Projeto de sensibilização e capacitação dos catadores de resíduos recicláveis e reutilizáveis. Educação ambiental nas escolas e na comunidade de Cerro Largo visando um meio ambiente ecologicamente equilibrado - Programa Pensar o Amanhã. Projeto de Extensão da Universidade Federal da Fronteira Sul - Campus Cerro Largo. Cerro Largo, RS, 2017b.

WORLD BANK. What a Waste: A Global Review of Solid Waste Management. Disponível em: https://openknowledge.worldbank.org/ handle/10986/17388. Acesso em: 12 maio 2017. 